\title{
Genetic and environmental factors underlying keratinocyte carcinoma risk
}

\author{
Hélène Choquet, ${ }^{1}$ Sepideh Ashrafzadeh, ${ }^{2,3}$ Yuhree Kim, ${ }^{2,3}$ Maryam M. Asgari,, ${ }^{2,3}$ and Eric Jorgenson ${ }^{1}$ \\ ${ }^{1}$ Kaiser Permanente Northern California, Division of Research, Oakland, California, USA. ²Department of Dermatology, \\ Massachusetts General Hospital, Boston, Massachusetts, USA. ${ }^{3}$ Department of Population Medicine, Harvard Pilgrim \\ Health Care Institute, Harvard Medical School, Boston, Massachusetts, USA.
}

Recent large-scale GWAS and large epidemiologic studies have accelerated the discovery of genes and environmental factors that contribute to the risk of keratinocyte carcinoma (KC), which includes basal cell carcinoma (BCC) and squamous cell carcinoma (SCC). This Review summarizes the genomic regions associated with SCC and BCC risk, examines the genetic overlap between SCC and BCC, and discusses biological pathways involved in SCC and BCC development. Next, we review environmental factors that are associated with $\mathrm{KC}$ risk, including those that are shared between SCC and BCC as well as others that associated with only one type of KC. We conclude with a critical appraisal of current research and potential directions for future research.

Authorship note: $\mathrm{HC}$ and $\mathrm{SA}$ contributed equally to this work.

Conflict of interest: MMA has received grant funding to her institution from Pfizer.

Copyright: () 2020, American Society for Clinical Investigation.

Reference information: JCI Insight. 2020;5(10):e134783. https://doi.org/10.1172/jici. insight.134783.

\section{Introduction}

Keratinocyte carcinoma (KC), which includes squamous cell carcinoma (SCC) and basal cell carcinoma (BCC), is one of the most common malignancies worldwide (1). Over the past decades, KC incidence in the US has increased from 2.4 million people diagnosed in 2006 to 3.3 million diagnosed in 2012 (1). As KCs disproportionately affect older individuals and as the aging population in the US grows, KCs will continue to afflict more Americans, thereby posing an increasing burden on the health care system. A better understanding of the etiology of KCs can aid treatment and prevention efforts.

Both SCC and BCC are derived from epidermal keratinocytes (2) (Figure 1) but diverge along distinct oncogenic pathways, giving rise to two phenotypically distinct tumors (3). Pigmentary traits, such as fair skin, light eye color, blonde or red hair, and a tendency to sunburn are strong and independent risk factors for both SCC and BCC (4). Genetic risk factors that affect pigment reflect shared disease risk, but other genetic risk factors appear specific to SCC or BCC. Environmental risk factors, including UV radiation exposure and immunosuppression, are shared between SCC and BCC $(5,6)$; however, tobacco use and photosensitizing medications are specifically associated with SCC development, while ionizing radiation is associated with BCC development (7-10).

Herein, we review and discuss published findings on the genetic and environmental factors that drive the keratinocyte toward two phenotypically distinct tumors (SCC and BCC). First, we summarize genetic factors involved in BCC and SCC development, including the genetic overlap between SCC and BCC and biological pathways elucidated through recent GWAS studies. Second, we highlight environmental factors that affect SCC and BCC risk by summarizing epidemiologic studies and meta-analyses. Understanding the shared and unique genetic and environmental risk factors can help guide treatment and prevention strategies for patients prone to SCC, BCC, or both.

\section{Genetic factors}

Genetic factors play an important role in KC susceptibility and have been identified through family and family history studies, the presence of $\mathrm{KC}$ as a feature of rare hereditary syndromes, and genetic association studies. GWAS have recently identified many new KC specific genetic risk factors, which are summarized along with other known genetic risk factors in Figure 2. Multiple genetic factors affect the risk of both $\mathrm{BCC}$ and SCC, while others only affect the risk of one type of $\mathrm{KC}$.

Heritability of $K C$. A small number of family studies have been conducted that demonstrate the important contribution of genetic factors to KC susceptibility. A single twin study in Nordic populations estimated a heritability of $43.0 \%(95 \% \mathrm{CI}, 26.0 \%-59.0 \%)$ for $\mathrm{KC}(11)$. In a community-based setting, family history of 

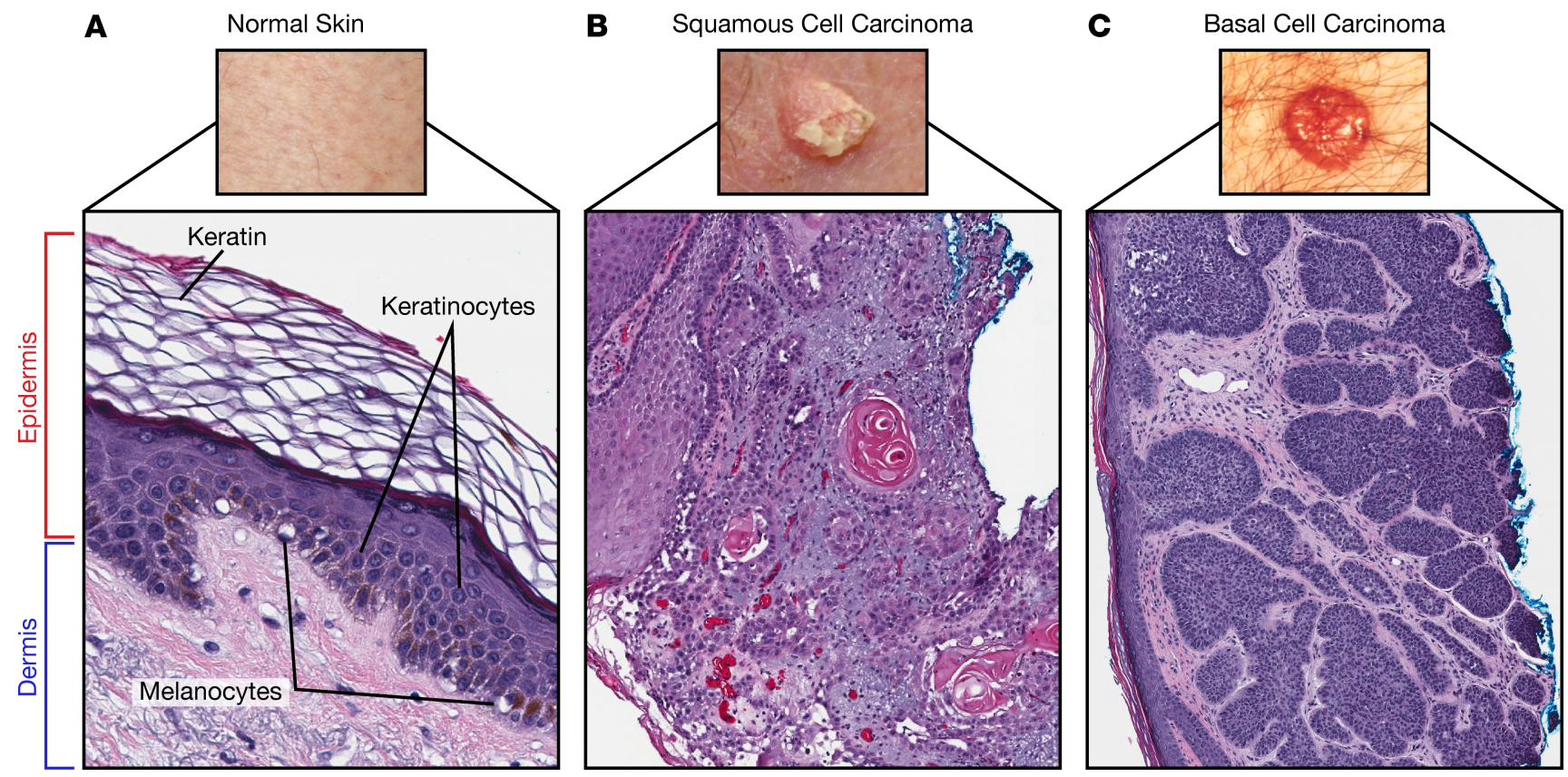

Figure 1. Normal skin structure and keratinocyte carcinomas. (A) Normal skin architecture showing composition of the dermis and epidermis (magnification 10x). The epidermis contains keratinocytes, which give rise to (B) squamous cell carcinoma (magnification 40x) and (C) basal cell carcinoma (magnification 40x). Images of SCC and BCC were taken from the National Cancer Institute (https://www.cancer.gov). Illustrated by Rachel Davidowitz.

$\mathrm{KC}$ has also been associated with a 4-fold higher risk of SCC (OR $=4.0 ; 95 \% \mathrm{CI}, 2.5-6.5)$ (12). More recently, a study based on genome-wide array data and self-reported $\mathrm{KC}$ history found a heritability of $14.0 \%$ (95\% CI, 5.6\%-22.4\%) for KC overall and 17.0\% (95\% CI, 7.0\%-27.0\%) for BCC (13). As such array-based heritability estimates reflect only the additive component of the genetic risk, they are typically lower than family-based estimates. Heritability estimates should also be considered in the context of the populations from which they have been derived. Changes in environmental exposures, particularly sun exposure in the case of skin cancer, can alter the proportion of disease risk that is assigned to genetic factors. Nonetheless, it is clear that genetic variation contributes substantially to individual differences in KC susceptibility.

Genetic syndromes associated with KC predisposition. More than 20 rare heritable disorders associated with an increased risk of KC have been reported in the literature (14-16) (Table 1). Some syndromes are associated with multiple BCCs, some with multiple SCCs, and some with both BCC and SCC. For example, Gorlin's and Bazex-Dupré-Christol syndromes are associated with the development of multiple BCCs, and the genes implicated are either involved in the sonic hedgehog (SHH) signaling pathway (i.e., ACTRT1, PTCH1, PTCH2, and SUFU) or encode proteins that affect DNA replication and repair functions (i.e., $U B E 2 A$ ). In contrast, multiple self-healing squamous epithelioma (also known as Ferguson-Smith disease) is an autosomal-dominant inherited disease caused by mutations in TGFBR1, leading to the formation and spontaneous regression of multiple SCCs (17). Other disorders, including xeroderma pigmentosum, Bloom, Werner, and Rothmund-Thomson syndromes, have a predominantly elevated risk of BCC as well as an increased risk of SCC. The genes implicated in these syndromes affect nucleotide excision repair (i.e., $X P A-X P G$ and $X P V$ ) and chromosomal stability (i.e., RECQL2-4). Together, the genes associated with these syndromes implicate biological pathways and functions underlying KC susceptibility.

GWAS - recent insights. In the last decade, GWAS have accelerated the discovery of genetic determinants of SCC and BCC. In 2016, 3 GWAS of SCC risk were published (18-20) that identified 16 genetic risk loci in subjects of European ancestry (Table 2). The first GWAS, conducted by Asgari et al. (18), consisted of 7701 SCC cases and 60,166 controls, reported 11 loci associated at a genome-wide level of significance $(P<5 \times$ $10^{-8}$ ) with SCC risk; these include FOXP1, TPRG1/TP63, SLC45A2, IRF4, HLA-DQA1, BNC2/CNTLN, TYR, $O C A 2, H E R C 2, D E F 8$, and ASIP/RALY. The second GWAS (20) reported DEF8 as the only genome-wide significant locus in a meta-analysis combining 1276 SCC cases and 13,356 controls. The third and most recent GWAS, totaling 7404 cases and 292,076 controls, confirmed loci near SLC45A2, IRF4, BNC2/CNTLN, TYR, OCA2, HERC2, and $A S I P / R A L Y$ and identified 5 additional genome-wide significant SCC loci, including an 


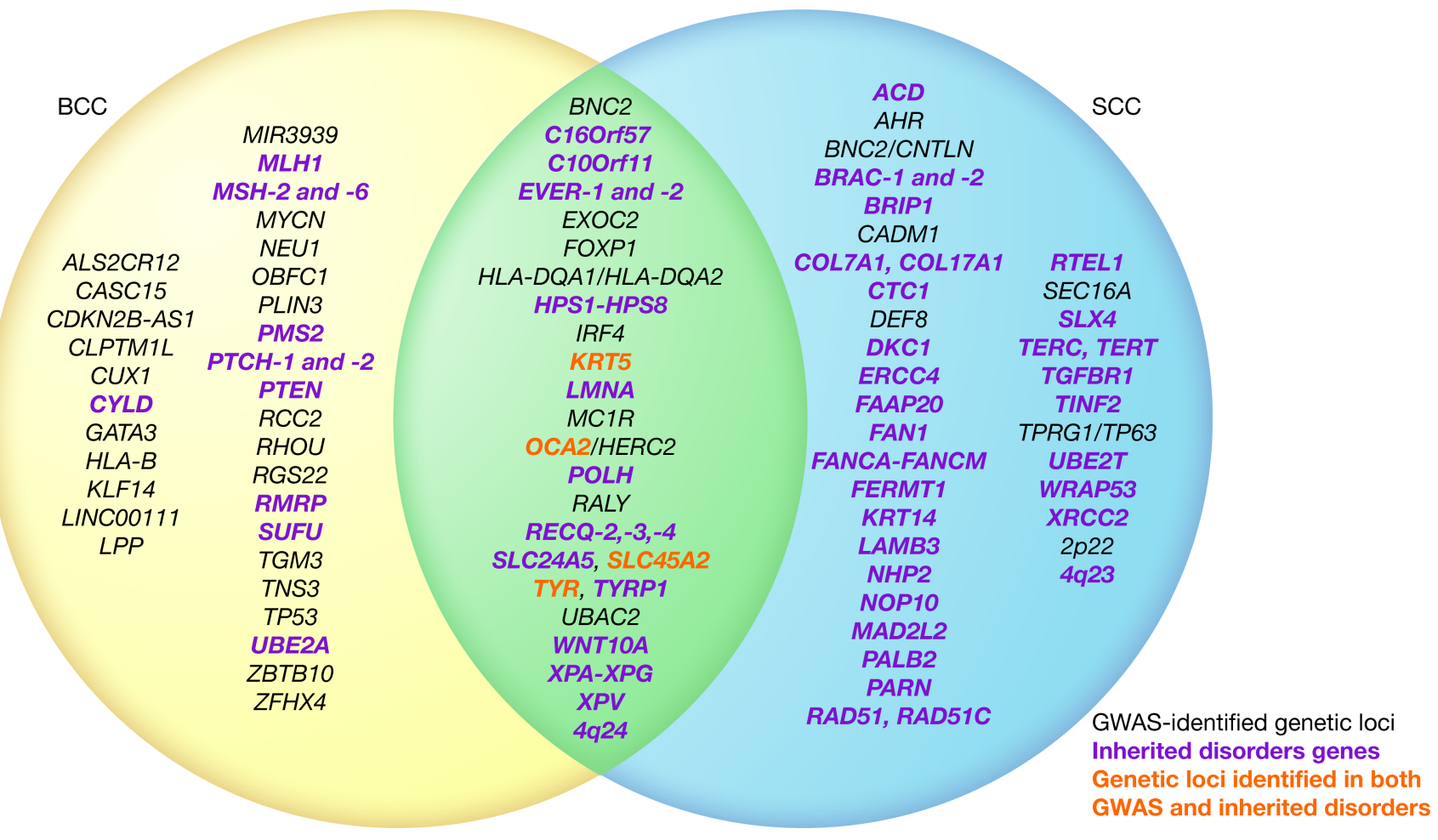

Figure 2. Venn diagram of KC genetic factors. While squamous cell carcinoma (SCC) and basal cell carcinoma (BCC) have several independent risk factors, both share a subset of associated genetic loci. CWAS-identified genetic loci (black) associated at a genome-wide level of significance $\left(P<5.0 \times 10^{-8}\right)$ with SCC, BCC, or both. Inherited disorders genes (green). Genetic loci identified in both CWAS and inherited disorders (red). Cenetic loci are order alphabetically. Illustrated by Rachel Davidowitz.

intergenic region on chromosome 2p22, AHR, SEC16A, CADM1, and MC1R (19). Together, all of the SCC-associated SNPs have a $62 \%$ population-attributable risk, meaning that more than half of the risk of SCC could be eliminated if the effects of all risk alleles were removed from the population (21).

Six GWAS studies $(22-27)$ and two follow-up candidate gene studies $(28,29)$ that examined BCC risk in European and Icelandic populations identified 33 loci (Table 2). The most recent and largest GWAS (22) consisted of 17,187 BCC cases and 287,054 controls, validated 17 previously reported loci (24-29), and identified an additional 14 susceptibility loci that reached genome-wide significance. Together, these SNPs explain $10.98 \%$ of the heritability of BCC (22). GWAS have contributed substantially to our understanding of genetic risk factors for both SCC and BCC.

Shared genetic susceptibility loci between SCC and BCC. Individual GWAS have focused on either BCC or SCC; though, many risk loci are shared between them. We reviewed recent GWAS of BCC and SCC and identified 9 genetic loci (FOXP1, SLC45A2, HLA-DQA1/HLA-DQA2, IRF4, BNC2, TYR, OCA2/HERC2, $M C 1 R$, and $R A L Y$ ) that have been associated with both BCC and SCC at a genome-wide level of significance $(18,19,22,23)$ (Table 3$)$. At each of these loci, the same lead SNP associated with both diseases and showed a directionally consistent effect in both GWAS, with the exceptions of FOXP1 and HLA$D Q A 1 / H L A-D Q A 2$. In a GWAS of SCC (18), rs62246017 was reported to be the lead SNP at FOXP1, while rs2116709 was the lead SNP at this locus in a GWAS of BCC (22). Similarly, lead SNPs rs4455710 and rs9275642 at the HLA-DQA1/HLA-DQA2 locus were relatively close to each other (76.1 kb apart) but were not correlated in European ancestry populations $\left(R^{2}=0.027, \mathrm{D}^{\prime}=0.33\right)$, potentially indicating two independent signals in the same genomic region. Finally, two SNPs (rs12210050 near EXOC2 and rs7335046 near $U B A C 2$ ), first identified in a GWAS of BCC (23), were then tested for association with SCC risk and showed suggestive evidence of association.

Many of the shared loci correspond to genes involved in the pigmentation pathway, which likely impart their effect on $\mathrm{KC}$ risk through an interaction with UV exposure. Other loci appear to affect KC risk via different mechanisms, such as Notch signaling and chromosomal instability. Future studies that use large populations with subjects who have validated SCC and BCC diagnoses, including subjects who develop 
Table 1. Summary of inherited disorders associated with an increased risk of KC

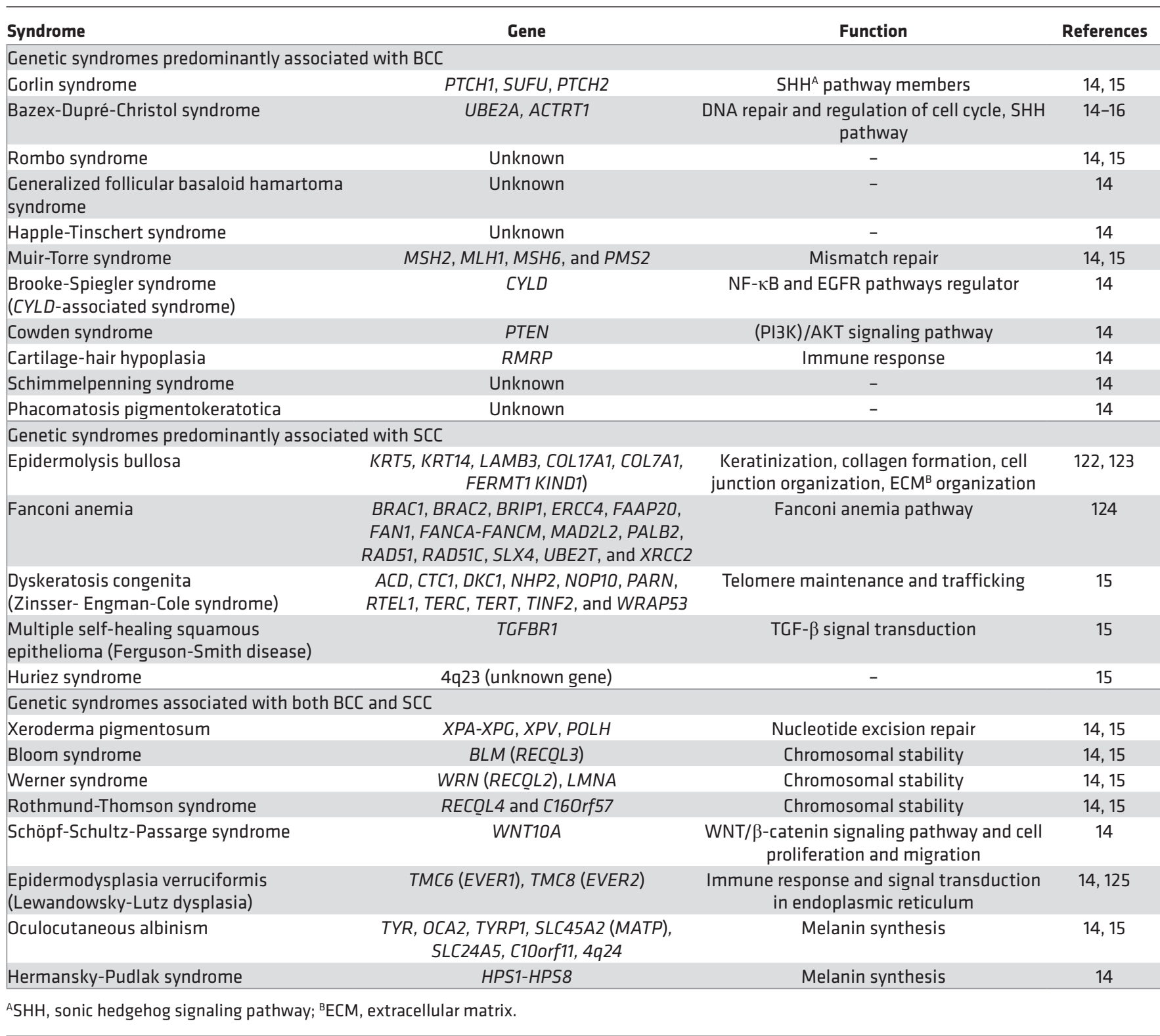

both types of KC, can help to clarify the role of shared genetic risk factors in disease etiology. To date, the lack of this information remains a key impediment to a better understanding of the role of genetic risk factors that are shared across KC and those that are specific to SCC or BCC.

\section{Biological pathways involved in KC development}

Several biological pathways influence the risk of both BCC and SCC. The two largest genetic-association studies of SCC (18) and BCC (22) identified multiple risk loci near pigmentation genes (for SCC SLC45A2, IRF4, TYR, HERC2, DEF8, and RALY; for BCC MC1R, IRF4, TYRP1, HERC2, LPP, and BNC2), supporting the well-established role of lighter pigmentation, and its interaction with $U V$ radiation exposure, in the risk of $\mathrm{KC}$. The association of genetic variants in regions of FOXP1 and IRF4 also implicate Notch signaling (30-32) in both SCC and BCC susceptibility. Patients with Bloom, Werner, and Rothmund-Thomson syndromes are at increased risk of BCC and SCC, implicating chromosomal instability as another shared KC risk factor $(14,15)$. Moreover, altered telomere maintenance has been associated with SCC secondary to dyskeratosis congenita, and genetic variants in the region of $O B F C 1$ (telomere length-regulating gene) have been associated with $\operatorname{BCC}(15,22)$. 
Table 2. Lead genome-wide significant SNP for each KC locus

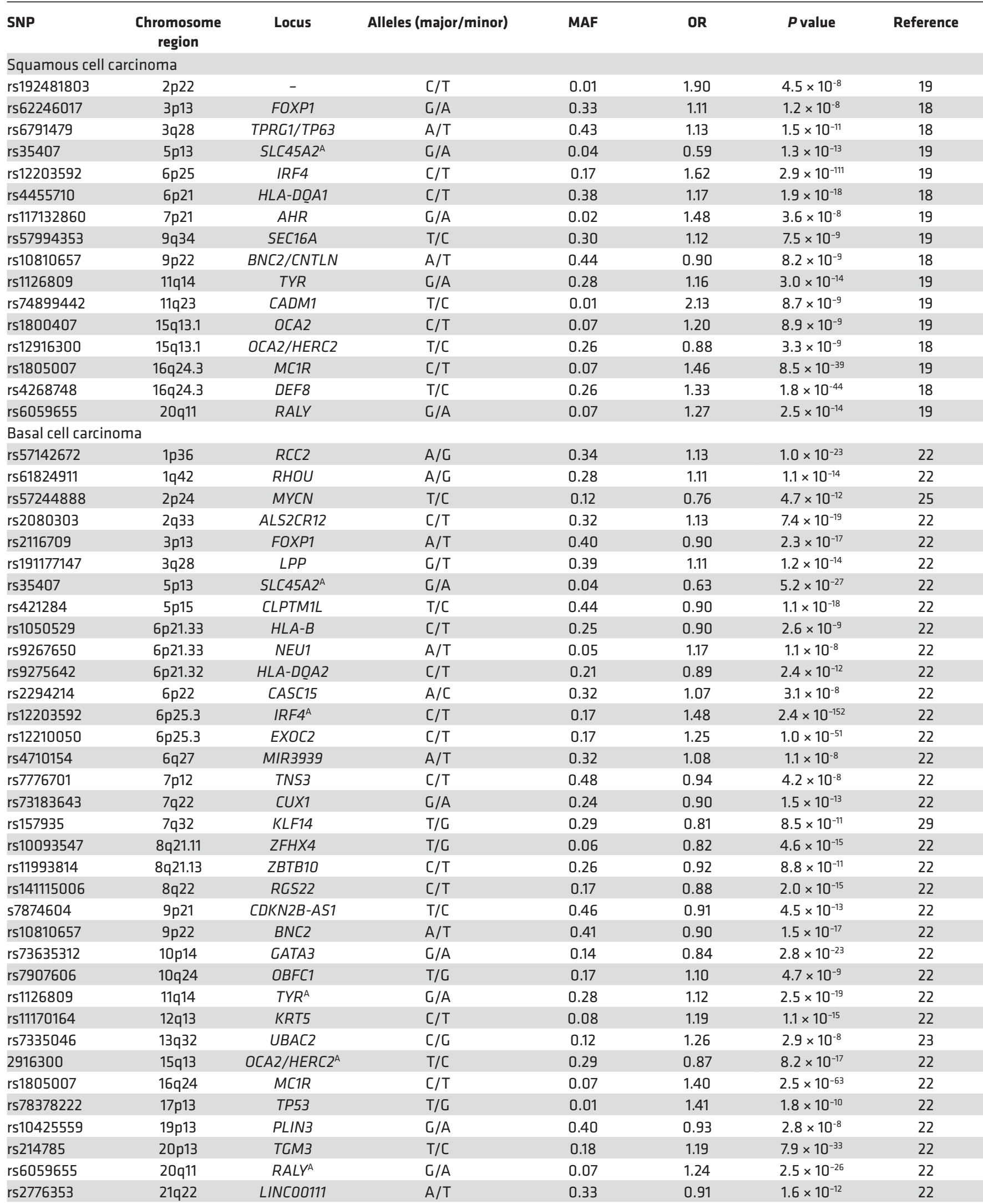

rrs $1^{A}$ Initially discovered via candidate gene studies. SNPs reported in this table achieved genome-wide level of significance in at least one study. Values reported for each SNP are from the most recent study. 
Table 3. Genetic overlap between SCC and BCC risks

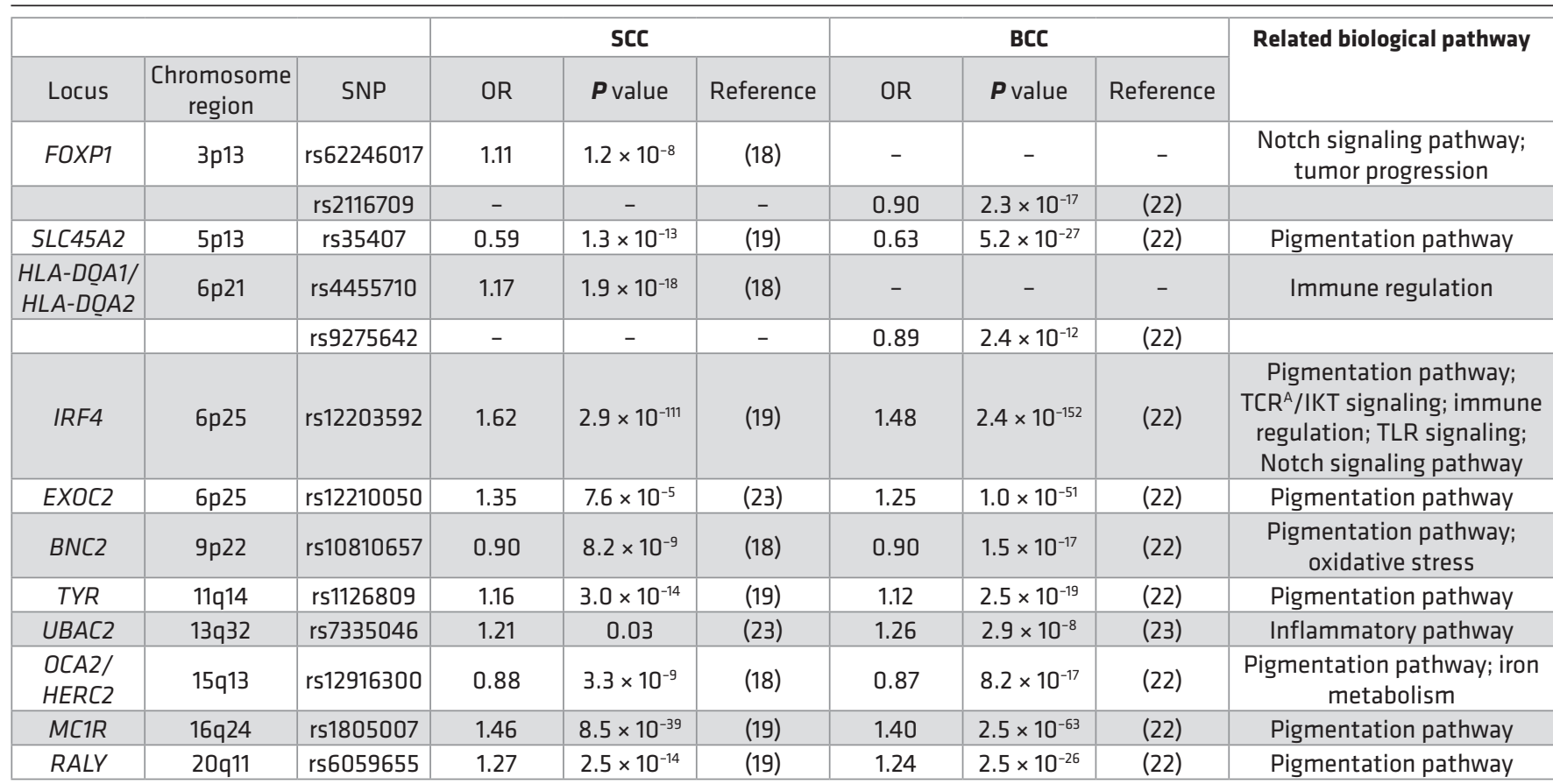

${ }^{A} T C R, T$ cell receptor.

Conversely, the SHH signaling pathway influences the risk of BCC, but not SCC, as individuals with Gorlin's and Bazex-Dupré-Christol syndromes have a greatly increased risk of multiple BCCs $(14,15)$. Additionally, while GWAS of both BCC and SCC have identified several susceptibility loci in the HLA region (e.g., $H L A-B, H L A-D Q A 1, H L A-D Q A 2, H L A-D Q A 16, H L A-D Q B 1$, and $H L A-D P A 1)(18,19,22,33$, $34)$, there appear to be independent signals associated with each type of $\mathrm{KC}$, indicating that risk factors involved in immune surveillance maybe be specific to either BCC or SCC. Furthermore, risk alleles in $H L A-D Q A 1$ (rs4455710) predispose to in situ SCCs, which are localized to the epidermis, and rs4126997 in class II HLA ( $H L A-D Q A 1$ and $H L A-D Q B 1$ ) was associated with invasive compared with in situ SCC (35). Future studies that explore the role of HLA genetic risk loci in patients who develop SCC only, BCC only, and both SCC and BCC may be able to clarify the role of immune surveillance genes in KC susceptibility.

\section{Environmental factors}

The epidermis is subject to many external environmental factors that cause deleterious mutations, which accumulate and eventually lead to keratinocyte carcinogenesis (3). UV radiation and immunosuppression contribute to both BCC and SCC development. Meanwhile, certain environmental factors, such as ionizing radiation, chronic inflammation, and cigarette smoke, affect the risk of only BCC or SCC. These factors are summarized in Figure 3.

\section{Radiation}

UV radiation. UV radiation, particularly UVB, contributes to an estimated $90 \%$ of all $\mathrm{KCs}(5,36,37)$ and is the most important environmental risk factor for both BCC and SCC. Moreover, other factors (e.g., fair pigmentation, older age) that contribute to KC risk often affect an individual's susceptibility to UV radiation. The intensity and cumulative dose of UV radiation differentially effect SCC and BCC risk. Intense, episodic sun exposure that causes severe sunburns increases BCC risk, while cumulative sun exposure increases SCC risk (38). UV radiation from indoor tanning beds also significantly increases both SCC relative risk (RR; 1.67, 95\% CI 1.29-2.17) and BCC risk (RR 1.29, 95\% CI 1.08-1.53) (39). The carcinogenesis of UV radiation is multimodal, involving direct DNA damage, inflammation, and immune suppression (40). Notably, UVB radiation causes a characteristic DNA mutation (particularly in the gene encoding tumor suppressor p53) termed "signature 7" in 


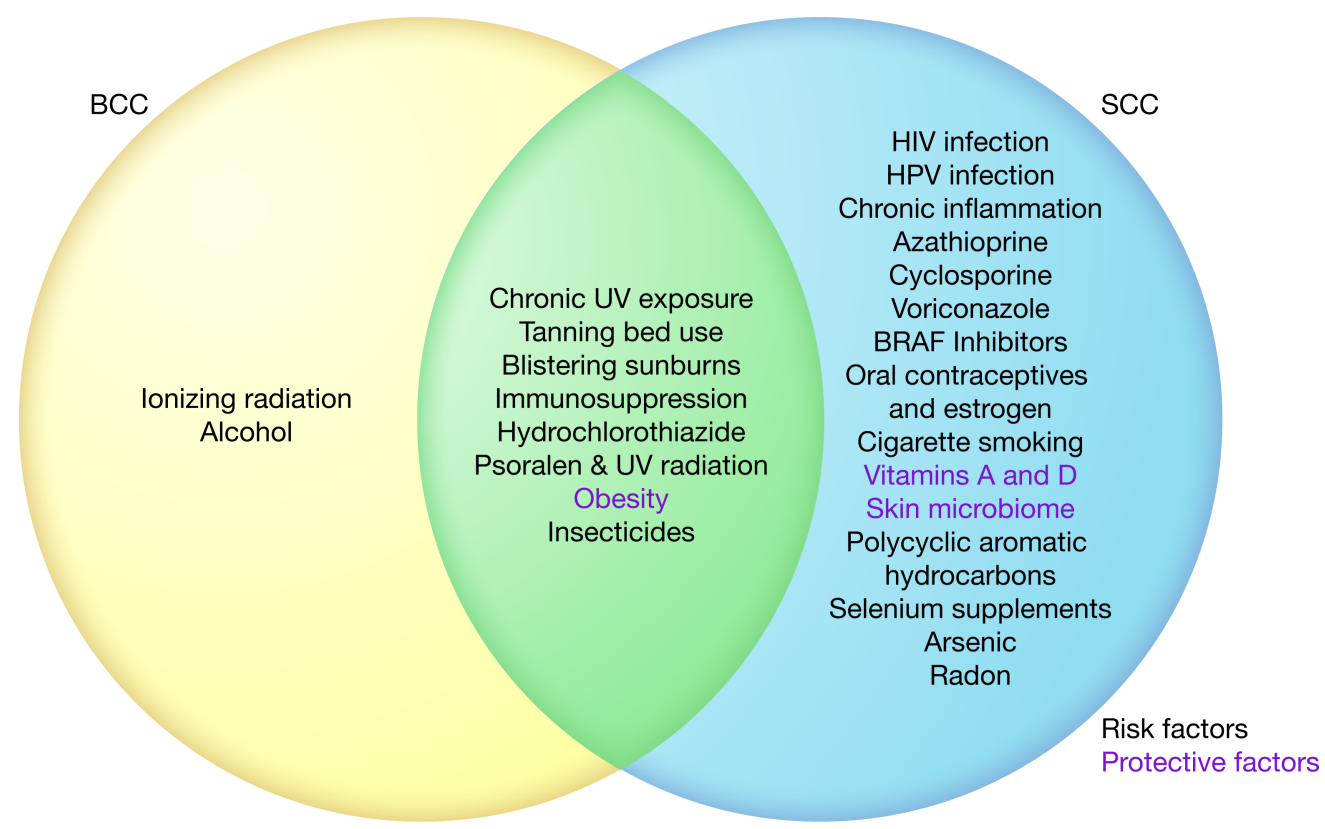

Figure 3. Venn diagram of environmental risk factors and protective factors for KCs. This diagram illustrates associations noted in the literature between environmental factors and KC risk, not necessarily causal relationships. Protective (green) and risk factors (red) are shown. Illustrated by Rachel Davidowitz.

keratinocytes by generating cyclobutene pyrimidine dimers that undergo transition mutations at cytosine bases (i.e., C:G>T:A transitions and CC:GG>TT:AA double-nucleotide substitutions) $(41,42)$. UVA radiation leads to the production of free radicals that oxidize nucleotides, and when combined with psoralen (such as in PUVA therapy), causes a unique signature marked by DNA cross-linkage (43).

Ionizing radiation. Ionizing radiation (from radiotherapy; x-rays; occupational exposure; total body irradiation; atomic bombs) increases the risk of BCCs and potentially SCCs through several carcinogenic mechanisms, including direct DNA damage, genomic instability, and cell apoptosis $(44,45)$. Natural history studies of atomic bomb survivors suggest that BCC risk increases with the dose of radiation exposure and younger age of initial radiation exposure (46). Meanwhile, results from studies to determine the effect of ionizing radiation on SCC risk have been mixed, with one study on individuals who underwent therapeutic radiation finding a higher total number of BCCs but no effect on SCCs (BCC RR 2.3, 95\% CI 1.7-3.1; SCC RR 1.0, 95\% CI 0.5-1.9). Another study found increased risk of both BCC and SCC in sites of prior radiation (BCC OR 3.30, 95\% CI 1.60-6.81; SCC OR 2.94, 95\% CI 1.30-6.67), particularly for those irradiated for acne $(45,47)$. Further research is necessary to investigate the role of ionization radiation on SCC risk.

\section{Comorbidities}

Immunosuppression. Chronic immunosuppression, which can occur due to organ transplant medications, chronic leukemias and lymphomas, and infection with HIV, is an established major risk factor for SCC and, to a lesser extent, BCC (48-50). In contrast to the general population, solid-organ transplant recipients, particularly heart and lung transplants recipients, tend to develop SCC more often than BCCs $(51,52)$. Patients with chronic lymphocytic leukemia (CLL) have both higher incidence and more aggressive forms of SCC and BCC (53); a case-control study found that patients with CLL were significantly more likely to have SCC metastasis and die from metastasis, with an estimated cumulative 5-year incidence of metastasis of $18 \%$ compared with no metastasis among non-CLL patients (49). The tumorigenic effect of immunosuppression is suspected to be secondary to a weak immune surveillance that cannot eradicate precancerous keratinocytes $(49,54)$. In particular, immune surveillance is thought to affect SCC pathogenesis more than BCC pathogenesis, as SCCs express class I HLA proteins while BCCs do not; thus, providing one potential reason why immunosuppression leads to more SCC development than BCC development (55).

Chronic inflammation. Chronic inflammation increases the risk of SCC development and progression. Approximately $1 \%$ of all skin cancers, $95 \%$ of which are SCC, arise in chronically inflamed skin, 
such as sites of scars, burns, and ulcers (56). While inflammation under normal conditions helps defend hosts and regenerate damaged tissues, chronic inflammation produces ROS and reactive nitrogen intermediates that cause DNA damage, leading to genomic instability and tumorigenesis (57).

$B M I$. Obesity and BMI ( $\left.\geq 30 \mathrm{~kg} / \mathrm{m}^{2}\right)$ have a protective effect on $\mathrm{KC}$ risk. Compared with normal weight individuals, overweight and obese individuals have reduced risks of $\mathrm{KC}$ development (RR 0.93, 95\% CI 0.89-0.99, and RR 0.86, 95\% CI 0.80-0.91, respectively) (58). This inverse association between BMI and $\mathrm{KC}$ risk tends to be stronger in women and has not been consistently found in men (59). The pathophysiology behind the lower KC risk with obesity is unknown, but it is hypothesized that individuals with higher BMI may have reduced outdoor time and therefore less UV exposure or that higher estrogen levels due to obesity are protective against BCC and SCC, as seen in mouse models $(58,60)$.

$H P V$. Certain viral infections, such as the $\beta$-subtype of the HPV, have been associated with an increased SCC risk (61). A meta-analysis, including 14 studies (over 3000 cases and 6000 controls), found increased odds of SCC with HPV infection (pooled OR 1.4, 95\% CI 1.2-1.7), particularly with HPV types 5, 8, $15,17,20,24,36$, and 38 (7). Experimental models have suggested that the mechanism of action for the increased SCC risk is due to the ability of $\beta$-HPV to promote proliferation and circumvent UV-induced cellular stresses, thus allowing for the persistence of keratinocytes that accumulate UV mutations that promote progression toward malignancy (62).

$H I V$. HIV infection may also contribute to KCs. Individuals with HIV have a dose response to developing SCC based on their CD4 ${ }^{+} \mathrm{T}$ cell counts and viral load; in 2017, a study found that patients with HIV who have $\mathrm{CD}^{+} \mathrm{T}$ cell counts $<200$ cells $/ \mathrm{mL}$ and viral loads $\geq 10,000$ copies $/ \mathrm{mL}$ have a $222 \%$ increased risk of developing SCC (50). No clear correlation between HIV infection and BCC has been found, however. The mechanism of HIV carcinogenesis is thought to be related to chronic immunosuppression.

Skin microbiome. In contrast to viral infections, a recent study has suggested the skin microbiome may protect against skin cancer (63). Certain Staphylococcus epidermidis strains isolated from healthy human skin produce an adenine analog, 6- $N$-hydroxyaminopurine, which selectively inhibits DNA polymerase in SCC but not in normal keratinocytes (63). Mice colonized with 6 - $N$-hydroxyaminopurine-expressing $S$. epidermidis develop fewer UV-induced tumors compared with mice colonized with bacterial strains that do not produce the analog (63). Given the budding nature of microbiome research, more studies are needed to better characterize the role of the skin microbiome in $\mathrm{KC}$ carcinogenesis (64).

\section{Medications}

Immunosuppressants. While immunosuppression is known to increase $\mathrm{KC}$ risk, several immunosuppressants increase $\mathrm{KC}$ risk through direct mutagenic effects that are independent of their immunosuppressive roles $(65,66)$. For example, azathioprine has been found to increase UVA photosensitivity, leading to increased oxidative DNA damage (67). The calcineurin inhibitor cyclosporine also has direct tumorigenic effects: cyclosporine enhances tumor growth in mice with severe combined immunodeficiency (66). Moreover, in transplant patients, those who received a combination of cyclosporine, azathioprine, and prednisone had a 3- to 4.2-fold increased risk of $\mathrm{KC}$ compared with those receiving only azathioprine and prednisone (68). Another study showed that cyclosporine-mediated inhibition of calcineurin (and therefore nuclear factor of activated T cells) counteracts p53-dependent cellular senescence (69). Other mechanisms of cyclosporine carcinogenesis include increased expression of VEGF (which promotes cell proliferation and tumor vascularity), increased epithelial-mesenchymal transition, and decreased apoptosis $(70,71)$.

Oral contraceptive pills and estrogen. Oral contraceptive pills and estrogen exposure are associated with increased $\mathrm{KC}$ risk among women $(72,73)$. One study found that oral contraceptive use and duration of use ( $\geq 7$ years) increase the odds of SCC (OR 1.4, 95\% CI 1.1-1.8) and KCs (SCC OR 1.5, 95\% CI 1.1-2.0; BCC OR 1.5, 95\% CI 1.1-2.0), respectively (74). Another study that followed over 46,000 women found that later menopause age was associated with a 50\% increased risk of BCC (RR 1.50, 95\% CI 1.04-2.17 for $\geq 55$ years), and hormone therapy during menopause was associated with a $16 \%$ increased risk of BCC (RR 1.16, 95\% CI 1.03-1.30) (75). Other studies have similarly found modest increases in BCC risk with menopausal hormone therapy (76). Estrogen exposure is thought to make the epidermis more sensitive to the damaging effects of UV radiation $(75,77)$. However, further studies are necessary to confirm findings related to oral contraceptive pills, as confounders may have affected results. 
Other medications. Certain medications predominantly increase the risk of SCC (78). For example, the antifungal drug voriconazole increases cutaneous photosensitivity and SCC risk among immunosuppressed adults and children through an unknown mechanism (79). BRAF inhibitors, which are targeted therapies for melanoma, have also been associated with increased SCC development, with approximately 15\%-30\% of BRAF inhibitor-treated patients developing SCCs or keratoacanthomas (80). The mechanism of carcinogenesis for these inhibitors is likely secondary to the activation of the MAPK pathway in cells with preexisting mutations in RAS or RTK, leading to cancer cell proliferation (80). Certain photosensitizing drugs (e.g., thiazides) or PUVA therapy also increase SCC risk and BCC to a lesser extent $(10,81,82)$. A meta-analysis that combined 9 studies found that thiazide use was associated with increased SCC risk (OR 1.86, 95\% CI 1.23-2.80) and slightly increased BCC risk (OR 1.19, 95\% CI 1.02-1.38) (81). Additionally, a 30-year prospective cohort study following 1380 patients showed that PUVA therapy resulted in a significantly elevated SCC incidence and modestly elevated BCC incidence (82).

\section{Vitamin intake}

Considering that vitamin $\mathrm{A}$ is involved with the growth, differentiation, and maintenance of keratinocytes, it is not surprising that vitamin A intake is associated with a decreased risk of SCC (83). A randomized controlled trial assigned nearly 2,300 adults who had a history of greater than 10 actinic keratoses and up to 2 SCCs or BCCs to either receive daily oral retinol $(25,000 \mathrm{IU})$ or a placebo supplement for 5 years. Compared with individuals who took the placebo supplement, individuals who took retinol had a lower risk of developing a first new SCC (HR 0.74, 95\% CI 0.56-0.99) but not BCC (HR 1.06, 95\% CI 0.86-1.32) (83). In a more recent study, increased vitamin A intake (measured using self-reported dietary information from 123,570 adults) was associated with reduced SCC risk (84). At present, synthetic retinoids are given to high-risk populations for chemoprevention of SCC with positive effects; although, dietary vitamin A may be an alternative strategy $(85,86)$. Vitamin B3 (nicotinamide), which has known antiinflammatory and photoprotective effects, has also been found to protect against $\mathrm{KC}$ in high-risk individuals. A randomized control trial of 72 immunocompetent adults with 4 or more palpable actinic keratoses (precancerous skin lesions) who were randomly assigned to take daily nicotinamide (500 mg or $1000 \mathrm{mg}$ daily) or placebo for four months found that nicotinamide participants had a $29 \%-35 \%$ relative reduction in their actinic keratosis count $(P<0.01)$ and only two participants developed KCs compared with 11 participants in the placebo group (87). The first phase 3 randomized controlled trial of oral nicotinamide published in 2015 found similar protective effects, with 386 adults with history of two or more KCs who took 500 mg nicotinamide twice daily developing $23 \%$ fewer KCs compared with adults taking placebo after 12 months $(P=0.02)$ (88). However, the authors found that nicotinamide's protective $\mathrm{KC}$ effects were no longer maintained at the six-month follow-up, suggesting that the chemopreventive effects are dependent on continuous intake of nicotinamide (88).

In contrast to seemingly protective effects of vitamins A and B3 on KC development, vitamin B9 (folate) has mixed effects (89). A prospective cohort study that followed 129,811 subjects over 10-14 years found no association between dietary or supplemental folate intake and KC risk, a finding that was reaffirmed in a subsequent meta-analysis of 13 randomized controlled studies on folate supplements $(90,91)$. However, a 2015 prospective study with 5880 participants found that higher folate intake was associated with increased risk of KCs in women but not in men; to explain their findings, the authors suggested KC modulation by hormones or that quickly dividing cancer cells may require higher levels of folate for DNA synthesis (89). More large-scale prospective studies are needed to establish whether a true relationship between folate and $\mathrm{KC}$ risk exists.

Evaluation of the role of vitamin D in KC carcinogenesis has also produced mixed results (92). Animal studies have shown that mouse keratinocytes lacking the vitamin D receptor (VDR) are hyperproliferative and have reduced rates of apoptosis and that VDR-knockout mice develop more BCCs and SCCs compared with WT mice, suggesting that vitamin D protects against KC formation $(93,94)$. Meanwhile, clinical studies on the association between vitamin $\mathrm{D}$ and $\mathrm{KC}$ development have found heterogeneous results, likely because UV exposure increases KC risk but also increases vitamin D levels (95). Sun exposure is a potential confounder in many studies examining this association and needs to be considered carefully in interpreting results (96). There is insufficient evidence as to whether vitamin D affects KC risk, but randomized controlled trials may help elucidate whether a true relationship exists (97). 


\section{Alcohol intake}

Increased alcohol intake and higher lifetime alcohol consumption may be weakly associated with higher KC risk $(98,99)$. In the Women's Health Initiative Cohort $(n=59,575)$, investigators found a higher risk of KCs among women who consumed more than 7 drinks per week compared with women who did not drink (98). As other studies have not found a relationship between KC risk and alcohol intake (100), it is unclear if alcohol has a causative effect on $\mathrm{KC}$ risk (e.g., through increasing oxidative stress and free radicals that damage DNA) or an associative role (e.g., heavy alcohol intake may be associated with increased medical surveillance due to alcohol-related medical conditions or high-risk behaviors, such as tanning and not using sun protection) (98).

\section{Cigarette smoking}

Smoking increases SCC risk but has shown no effect on BCC risk. A 2012 meta-analysis found that smoking increases the risk of SCC (OR 1.52, 95\% CI 1.15-2.0, 6 studies) but not BCC (OR 0.95, 95\% CI 0.82 1.09) (8). A more recent study that followed over $1,200,000$ women over 14 years also found increased SCC incidence (RR 1.22, 95\% CI 1.15-1.31) but decreased BCC incidence (RR 0.72, 95\% CI 0.66-0.79) (101). Additional studies are needed to examine the influence of cigarette smoking on $\mathrm{KC}$ risk.

\section{Chemical carcinogens}

Arsenic is associated with increased BCC and SCC risk (102) and can be present in groundwater, leading to nearly 200 million exposed individuals worldwide (103). Arsenic-induced BCCs often have multiple foci and tend to occur in non-sun-exposed areas more often than BCCs due to UV radiation, while arsenic-associated SCCs arise in arsenic-induced hyperkeratotic skin regions (104). The mechanism of arsenic carcinogenesis includes chromosomal abnormalities, cellular oxidative stress through upregulation of nicotinamide adenine dinucleotide phosphate oxidase, tissue inflammation, and immune dysfunction (105). Furthermore, arsenic increases UVB toxicity by enhancing signaling from caspase-9 and caspase-8, which promote keratinocyte apoptosis, thereby providing an explanation for arsenic-induced $\mathrm{KC}$ formation in sun-exposed regions (106).

Other chemicals associated with increased $\mathrm{KC}$ risk include insecticides, herbicides, fungicides, radon, and selenium supplementation (107-109). Finally, polylic aromatic hydrocarbons are associated with increased SCC in situ formation in mouse models (110). These chemicals have a wide range of carcinogenic mechanisms, including oxidative cellular stress, DNA mutations, and dysregulation of cellular pathways $(109,111)$.

\section{Modifiable risk factors}

While genetic predisposition is not modifiable, environmental risk factors, such as sun exposure, sun-protective behaviors, diet, and medications, can be altered to change KC risk. Preventative efforts based on these modifiable risk factors may have a greater benefit to those at an elevated risk of $\mathrm{KC}$ due to genetic or other factors. Among solid-organ transplant recipients, SCC risk can decrease by up to $50 \%$ in one year by taking daily low-dose oral retinoids (although the protective effects attenuate with time) $(112,113)$. Daily sunscreen use has also been shown to decrease KC risk among transplant recipients (114). Changing immunosuppressive medications known to increase $\mathrm{KC}$ risk such as azathioprine to other classes of immunosuppressive agents may also decrease KC risk. Furthermore, patients with HIV who have lower viral loads and higher $\mathrm{CD}^{+} \mathrm{T}$ cell counts, which often correlate with antiretroviral medication compliance, can also decrease their SCC risk $(115,116)$. Understanding modifiable risk factors for $\mathrm{KC}$ development is important, because it enables providers to counsel and patients to engage in behaviors and exposures that can decrease individual $\mathrm{KC}$ risk.

\section{Directions for future research}

In this Review, we have highlighted shared and unique genetic and environmental risk factors for BCC and SCC to better understand which patients are at highest risk for each of the subtypes of $\mathrm{KC}$ and how to best inform potential ways to modify associated risks. A better understanding of KC risk factors is important, as some environmental factors can be modified through behavior change and genetic mutations and/or diseases that predispose individuals to developing $\mathrm{KC}$ through can be targeted with novel therapeutics. Further elucidation of genetic and environmental factors that drive the keratinocytes toward two phenotypically distinct tumors may also contribute to better prediction of adverse effects of targeted therapies, such as vismodegib, for which smoothened inhibition is thought to activate other pathways that promote SCC 
formation (117-120). Thus, improved knowledge of the interaction of genetic and environmental risk factors for KCs can inform the management of cutaneous side effects of smoothened inhibitor therapy (121).

Future studies are also needed to address the current knowledge gaps in KC etiology. For example, a large number of genetic and environmental risk factors have been identified; however, only a few interactions between genetic end environmental risk factors (i.e., UV exposure, hair color, number of sunburns, tanning ability, history of smoking, and immunosuppression) have been investigated $(18,22)$. While a number of KC genetic risk loci appear to be shared between BCC and SCC, well-powered genetic studies with reliable $\mathrm{KC}$ diagnoses and information on environmental risk factors are needed to accurately assess these risks and identify genetic loci that are specific to either BCC or SCC. These genetic and environmental determinants may be used in the future to inform precision medicine research so that therapies can be tailored to each individual.

\section{Acknowledgments}

This research was supported by the National Institute of Diabetes and Digestive and Kidney Diseases (R01 DK116738 to EJ), the National Eye Institute (R01 EY027004 to EJ), the National Cancer Institute (R01 CA166672 and R01 CA231264 to MA; R01 CA241623 to EJ and MMA), and the National Institute of Arthritis and Musculoskeletal and Skin Diseases (K24 AR069760 to MMA). We thank Jie Yin for assistance in preparation of images.

Address correspondence to: Eric Jorgenson, Division of Research, Kaiser Permanente Northern California, 2000 Broadway, Oakland, California 94612, USA Phone: 510.891.3473; Email: Eric.Jorgenson@kp.org.

1. Rogers HW, Weinstock MA, Feldman SR, Coldiron BM. Incidence estimate of nonmelanoma skin cancer (keratinocyte carcinomas) in the U.S. population, 2012. JAMA Dermatol. 2015;151(10):1081-1086.

2. Nehal KS, Bichakjian CK. Update on keratinocyte carcinomas. N Engl J Med. 2018;379(4):363-374.

3. Thieu K, Ruiz ME, Owens DM. Cells of origin and tumor-initiating cells for nonmelanoma skin cancers. Cancer Lett. 2013;338(1):82-88.

4. Zanetti R, et al. The multicentre south European study 'Helios'. I: Skin characteristics and sunburns in basal cell and squamous cell carcinomas of the skin. Br J Cancer. 1996;73(11):1440-1446.

5. [No authors listed]. Skin Cancer Facts \& Statistics. Skin Cancer Foundation. https://www.skincancer.org/skin-cancer-information/skin-cancer-facts/. Updated April 16, 2020. Accessed April 23, 2020.

6. Brewer JD, et al. Incidence of and risk factors for skin cancer after heart transplant. Arch Dermatol. 2009;145(12):1391-1396.

7. Chahoud J, et al. Association between $\beta$-genus human papillomavirus and cutaneous squamous cell carcinoma in immunocompetent individuals-a meta-analysis. JAMA Dermatol. 2016;152(12):1354-1364.

8. Leonardi-Bee J, Ellison T, Bath-Hextall F. Smoking and the risk of nonmelanoma skin cancer: systematic review and meta-analysis. Arch Dermatol. 2012;148(8):939-946.

9. Pedersen SA, Gaist D, Schmidt SAJ, Hölmich LR, Friis S, Pottegård A. Hydrochlorothiazide use and risk of nonmelanoma skin cancer: A nationwide case-control study from Denmark. J Am Acad Dermatol. 2018;78(4):673-681.e9.

10. Su KA, Habel LA, Achacoso NS, Friedman GD, Asgari MM. Photosensitizing antihypertensive drug use and risk of cutaneous squamous cell carcinoma. Br J Dermatol. 2018;179(5):1088-1094.

11. Mucci LA, et al. Familial risk and heritability of cancer among twins in Nordic countries. JAMA. 2016;315(1):68-76.

12. Asgari MM, Warton EM, Whittemore AS. Family history of skin cancer is associated with increased risk of cutaneous squamous cell carcinoma. Dermatol Surg. 2015;41(4):481-486.

13. Ge T, Chen CY, Neale BM, Sabuncu MR, Smoller JW. Phenome-wide heritability analysis of the UK Biobank. PLoS Genet. 2017;13(4):e1006711.

14. Castori M, Morrone A, Kanitakis J, Grammatico P. Genetic skin diseases predisposing to basal cell carcinoma. Eur J Dermatol. 2012;22(3):299-309.

15. Jaju PD, Ransohoff KJ, Tang JY, Sarin KY. Familial skin cancer syndromes: Increased risk of nonmelanotic skin cancers and extracutaneous tumors. J Am Acad Dermatol. 2016;74(3):437-451.

16. Bal E, et al. Mutations in ACTRT1 and its enhancer RNA elements lead to aberrant activation of Hedgehog signaling in inherited and sporadic basal cell carcinomas. Nat Med. 2017;23(10):1226-1233.

17. Goudie DR, et al. Multiple self-healing squamous epithelioma is caused by a disease-specific spectrum of mutations in TGFBR1. Nat Genet. 2011;43(4):365-369.

18. Asgari MM, et al. Identification of susceptibility loci for cutaneous squamous cell carcinoma. J Invest Dermatol. 2016;136(5):930-937.

19. Chahal HS, et al. Genome-wide association study identifies novel susceptibility loci for cutaneous squamous cell carcinoma. Nat Commun. 2016;7:12048.

20. Siiskonen SJ, et al. A genome-wide association study of cutaneous squamous cell carcinoma among European descendants. Cancer Epidemiol Biomarkers Prev. 2016;25(4):714-720.

21. Sordillo JE, Kraft P, Wu AC, Asgari MM. Quantifying the polygenic contribution to cutaneous squamous cell carcinoma risk. J Invest Dermatol. 2018;138(7):1507-1510. 
22. Chahal HS, et al. Genome-wide association study identifies 14 novel risk alleles associated with basal cell carcinoma. Nat Commun. 2016;7:12510.

23. Nan H, et al. Genome-wide association study identifies novel alleles associated with risk of cutaneous basal cell carcinoma and squamous cell carcinoma. Hum Mol Genet. 2011;20(18):3718-3724.

24. Stacey SN, et al. Common variants on $1 \mathrm{p} 36$ and $1 \mathrm{q} 42$ are associated with cutaneous basal cell carcinoma but not with melanoma or pigmentation traits. Nat Genet. 2008;40(11):1313-1318.

25. Stacey SN, et al. New basal cell carcinoma susceptibility loci. Nat Commun. 2015;6:6825.

26. Stacey SN, et al. Germline sequence variants in TGM3 and RGS22 confer risk of basal cell carcinoma. Hum Mol Genet. 2014;23(11):3045-3053.

27. Stacey SN, et al. A germline variant in the TP53 polyadenylation signal confers cancer susceptibility. Nat Genet. 2011;43(11):1098-1103.

28. Rafnar T, et al. Sequence variants at the TERT-CLPTM1L locus associate with many cancer types. Nat Genet. 2009;41(2):221-227.

29. Stacey SN, et al. New common variants affecting susceptibility to basal cell carcinoma. Nat Genet. 2009;41(8):909-914.

30. Qian Y, Du Z, Xing Y, Zhou T, Chen T, Shi M. Interferon regulatory factor 4 (IRF4) is overexpressed in human non-small cell lung cancer (NSCLC) and activates the Notch signaling pathway. Mol Med Rep. 2017;16(5):6034-6040.

31. Braccioli L, et al. FOXP1 promotes embryonic neural stem cell differentiation by repressing Jagged1 expression. Stem Cell Reports. 2017;9(5):1530-1545.

32. Wei H, et al. Cutting edge: Foxp1 controls naive CD8+ T cell quiescence by simultaneously repressing key pathways in cellular metabolism and cell cycle progression. J Immunol. 2016;196(9):3537-3541.

33. Ioannidis NM, et al. Gene expression imputation identifies candidate genes and susceptibility loci associated with cutaneous squamous cell carcinoma. Nat Commun. 2018;9(1):4264.

34. Liyanage UE, et al. Combined analysis of keratinocyte cancers identifies novel genome-wide loci. Hum Mol Genet. 2019;28(18):3148-3160.

35. Wang W, Jorgenson E, Whittemore AS, Asgari MM. Susceptibility loci-associated cutaneous squamous cell carcinoma invasiveness. J Invest Dermatol. 2018;138(3):557-561.

36. Glanz K, Buller DB, Saraiya M. Reducing ultraviolet radiation exposure among outdoor workers: state of the evidence and recommendations. Environ Health. 2007;6:22.

37. Narayanan DL, Saladi RN, Fox JL. Ultraviolet radiation and skin cancer. Int J Dermatol. 2010;49(9):978-986.

38. Zanetti R, et al. Comparison of risk patterns in carcinoma and melanoma of the skin in men: a multi-centre case-case-control study. Br J Cancer. 2006;94(5):743-751.

39. Wehner MR, Shive ML, Chren MM, Han J, Qureshi AA, Linos E. Indoor tanning and non-melanoma skin cancer: systematic review and meta-analysis. BMJ. 2012;345:e5909.

40. Mancebo SE, Wang SQ. Skin cancer: role of ultraviolet radiation in carcinogenesis. Rev Environ Health. 2014;29(3):265-273.

41. Alexandrov LB, Nik-Zainal S, Wedge DC, Campbell PJ, Stratton MR. Deciphering signatures of mutational processes operative in human cancer. Cell Rep. 2013;3(1):246-259.

42. Pfeifer GP, Besaratinia A. UV wavelength-dependent DNA damage and human non-melanoma and melanoma skin cancer. Photochem Photobiol Sci. 2012;11(1):90-97.

43. Nataraj AJ, Black HS, Ananthaswamy HN. Signature p53 mutation at DNA cross-linking sites in 8-methoxypsoralen and ultraviolet A (PUVA)-induced murine skin cancers. Proc Natl Acad Sci USA. 1996;93(15):7961-7965.

44. Li C, Athar M. Ionizing radiation exposure and basal cell carcinoma pathogenesis. Radiat Res. 2016;185(3):217-228.

45. Karagas MR, et al. Risk of basal cell and squamous cell skin cancers after ionizing radiation therapy. For The Skin Cancer Prevention Study Group. J Natl Cancer Inst. 1996;88(24):1848-1853.

46. Preston DL, et al. Solid cancer incidence in atomic bomb survivors: 1958-1998. Radiat Res. 2007;168(1):1-64

47. Lichter MD, Karagas MR, Mott LA, Spencer SK, Stukel TA, Greenberg ER. Therapeutic ionizing radiation and the incidence of basal cell carcinoma and squamous cell carcinoma. The New Hampshire Skin Cancer Study Group. Arch Dermatol. 2000;136(8):1007-1011.

48. Onajin O, Brewer JD. Skin cancer in patients with chronic lymphocytic leukemia and non-Hodgkin lymphoma. Clin Adv Hematol Oncol. 2012;10(9):571-576.

49. Mehrany K, Weenig RH, Lee KK, Pittelkow MR, Otley CC. Increased metastasis and mortality from cutaneous squamous cell carcinoma in patients with chronic lymphocytic leukemia. J Am Acad Dermatol. 2005;53(6):1067-1071.

50. Asgari MM, Ray GT, Quesenberry CP, Katz KA, Silverberg MJ. Association of multiple primary skin cancers with human immunodeficiency virus infection, CD4 count, and viral load. JAMA Dermatol. 2017;153(9):892-896.

51. Hartevelt MM, Bavinck JN, Kootte AM, Vermeer BJ, Vandenbroucke JP. Incidence of skin cancer after renal transplantation in The Netherlands. Transplantation. 1990;49(3):506-509.

52. Krynitz B, et al. Risk of skin cancer and other malignancies in kidney, liver, heart and lung transplant recipients 1970 to $2008--\mathrm{a}$ Swedish population-based study. Int J Cancer. 2013;132(6):1429-1438.

53. Brewer JD, et al. Increased incidence and recurrence rates of nonmelanoma skin cancer in patients with non-Hodgkin lymphoma: a Rochester Epidemiology Project population-based study in Minnesota. J Am Acad Dermatol. 2015;72(2):302-309.

54. Harwood CA, et al. The pathogenesis of cutaneous squamous cell carcinoma in organ transplant recipients. Br J Dermatol. 2017;177(5):1217-1224

55. Walter A, et al. Cancer-testis antigens and immunosurveillance in human cutaneous squamous cell and basal cell carcinomas. Clin Cancer Res. 2010;16(14):3562-3570.

56. Jellouli-Elloumi A, Kochbati L, Dhraief S, Ben Romdhane K, Maalej M. [Cancers arising from burn scars: 62 cases]. Ann Dermatol Venereol. 2003;130(4):413-416.

57. Tang L, Wang K. Chronic inflammation in skin malignancies. J Mol Signal. 2016;11:2.

58. Tang JY, et al. Lower skin cancer risk in women with higher body mass index: the women's health initiative observational study. Cancer Epidemiol Biomarkers Prev. 2013;22(12):2412-2415.

59. Perry DM, Barton V, Alberg AJ. Epidemiology of keratinocyte carcinoma. Curr Dermatol Rep. 2017;6(3):161-168. 
60. Mancuso M, et al. Modulation of basal and squamous cell carcinoma by endogenous estrogen in mouse models of skin cancer. Carcinogenesis. 2009;30(2):340-347.

61. Asgari MM, et al. Detection of human papillomavirus DNA in cutaneous squamous cell carcinoma among immunocompetent individuals. J Invest Dermatol. 2008;128(6):1409-1417.

62. Tommasino M. HPV and skin carcinogenesis. Papillomavirus Res. 2019;7:129-131.

63. Nakatsuji T, et al. A commensal strain of Staphylococcus epidermidis protects against skin neoplasia. Sci Adv. 2018;4(2):eaao4502. 64. Nagarajan P, et al. Keratinocyte carcinomas: current concepts and future research priorities. Clin Cancer Res. 2019;25(8):2379-2391. 65. O'Donovan P, et al. Azathioprine and UVA light generate mutagenic oxidative DNA damage. Science. 2005;309(5742):1871-1874. 66. Hojo M, et al. Cyclosporine induces cancer progression by a cell-autonomous mechanism. Nature. 1999;397(6719):530-534. 67. O'Donovan P, et al. Azathioprine and UVA light generate mutagenic oxidative DNA damage. Science. 2005;309(5742):1871-1874. 68. Jensen $P$, et al. Skin cancer in kidney and heart transplant recipients and different long-term immunosuppressive therapy regimens. J Am Acad Dermatol. 1999;40(2 Pt 1):177-186.

69. Wu X, et al. Opposing roles for calcineurin and ATF3 in squamous skin cancer. Nature. 2010;465(7296):368-372.

70. Walsh SB, et al. Cyclosporine a mediates pathogenesis of aggressive cutaneous squamous cell carcinoma by augmenting epithelial-mesenchymal transition: role of TGF $\beta$ signaling pathway. Mol Carcinog. 2011;50(7):516-527.

71. Tang X, et al. CP-31398 restores mutant p53 tumor suppressor function and inhibits UVB-induced skin carcinogenesis in mice. J Clin Invest. 2007;117(12):3753-3764.

72. Applebaum KM, Nelson HH, Zens MS, Stukel TA, Spencer SK, Karagas MR. Oral contraceptives: a risk factor for squamous cell carcinoma? J Invest Dermatol. 2009;129(12):2760-2765.

73. Asgari MM, Efird JT, Warton EM, Friedman GD. Potential risk factors for cutaneous squamous cell carcinoma include oral contraceptives: results of a nested case-control study. Int J Environ Res Public Health. 2010;7(2):427-442.

74. Kuklinski LF, Zens MS, Perry AE, Gossai A, Nelson HH, Karagas MR. Sex hormones and the risk of keratinocyte cancers among women in the United States: A population-based case-control study. Int J Cancer. 2016;139(2):300-309.

75. Cahoon EK, et al. Female estrogen-related factors and incidence of basal cell carcinoma in a nationwide US cohort. JClin Oncol. 2015;33(34):4058-4065.

76. Birch-Johansen F, Jensen A, Olesen AB, Christensen J, Tjønneland A, Kjær SK. Does hormone replacement therapy and use of oral contraceptives increase the risk of non-melanoma skin cancer? Cancer Causes Control. 2012;23(2):379-388.

77. Suresh R, Twigg A, Murase JE. The relationship between menopausal hormone therapy and keratinocyte carcinoma: A review. Int J Womens Dermatol. 2019;5(1):8-13.

78. Mansh M, et al. Voriconazole exposure and risk of cutaneous squamous cell carcinoma, Aspergillus colonization, invasive aspergillosis and death in lung transplant recipients. Am J Transplant. 2016;16(1):262-270.

79. Cowen EW, et al. Chronic phototoxicity and aggressive squamous cell carcinoma of the skin in children and adults during treatment with voriconazole. J Am Acad Dermatol. 2010;62(1):31-37.

80. Su F, et al. RAS mutations in cutaneous squamous-cell carcinomas in patients treated with BRAF inhibitors. $N$ Engl J Med 2012;366(3):207-215.

81. Shin D, Lee ES, Kim J, Guerra L, Naik D, Prida X. Association between the use of thiazide diuretics and the risk of skin cancers: a meta-analysis of observational studies. J Clin Med Res. 2019;11(4):247-255.

82. Stern RS, PUVA Follow-Up Study. The risk of squamous cell and basal cell cancer associated with psoralen and ultraviolet A therapy: a 30-year prospective study. J Am Acad Dermatol. 2012;66(4):553-562.

83. Moon TE, et al. Effect of retinol in preventing squamous cell skin cancer in moderate-risk subjects: a randomized, double-blind, controlled trial. Southwest Skin Cancer Prevention Study Group. Cancer Epidemiol Biomarkers Prev. 1997;6(11):949-956.

84. Kim J, Park MK, Li WQ, Qureshi AA, Cho E. Association of vitamin A intake with cutaneous squamous cell carcinoma risk in the United States. JAMA Dermatol. 2019;155(11):1260-1268.

85. Harwood CA, Leedham-Green M, Leigh IM, Proby CM. Low-dose retinoids in the prevention of cutaneous squamous cell carcinomas in organ transplant recipients: a 16-year retrospective study. Arch Dermatol. 2005;141(4):456-464.

86. Bavinck JN, et al. Prevention of skin cancer and reduction of keratotic skin lesions during acitretin therapy in renal transplant recipients: a double-blind, placebo-controlled study. J Clin Oncol. 1995;13(8):1933-1938.

87. Surjana D, Halliday GM, Martin AJ, Moloney FJ, Damian DL. Oral nicotinamide reduces actinic keratoses in phase II double-blinded randomized controlled trials. J Invest Dermatol. 2012;132(5):1497-1500.

88. Chen AC, et al. A phase 3 randomized trial of nicotinamide for skin-cancer chemoprevention. N Engl J Med. 2015;373(17):1618-1626.

89. Donnenfeld M, et al. Prospective association between dietary folate intake and skin cancer risk: results from the Supplémentation en Vitamines et Minéraux Antioxydants cohort. Am J Clin Nutr. 2015;102(2):471-478.

90. Vollset SE, et al. Effects of folic acid supplementation on overall and site-specific cancer incidence during the randomised trials: meta-analyses of data on 50,000 individuals. Lancet. 2013;381(9871):1029-1036.

91. Fung TT, Spiegelman D, Egan KM, Giovannucci E, Hunter DJ, Willett WC. Vitamin and carotenoid intake and risk of squamous cell carcinoma of the skin. Int J Cancer. 2003;103(1):110-115.

92. Tang JY, Fu T, Lau C, Oh DH, Bikle DD, Asgari MM. Vitamin D in cutaneous carcinogenesis: part II. J Am Acad Dermatol. 2012;67(5):817.e1-11.

93. Zinser GM, Suckow M, Welsh J. Vitamin D receptor (VDR) ablation alters carcinogen-induced tumorigenesis in mammary gland, epidermis and lymphoid tissues. J Steroid Biochem Mol Biol. 2005;97(1-2):153-164.

94. Ellison TI, Smith MK, Gilliam AC, MacDonald PN. Inactivation of the vitamin D receptor enhances susceptibility of murine skin to UV-induced tumorigenesis. J Invest Dermatol. 2008;128(10):2508-2517.

95. Holick MF. High prevalence of vitamin D inadequacy and implications for health. Mayo Clin Proc. 2006;81(3):353-373.

96. Aleisa A, Hurwitz S, Schmults CD, Waldman A. Change in sun-protective behavior after dermatologic surgery for skin cancer in high-risk patients [published ahead of print October 4, 2019]. Dermatol Surg. https://doi/org/10.1097/DSS.0000000000002201.

97. Wyatt C, Neale RE, Lucas RM. Skin cancer and vitamin D: an update. Melanoma Manag. 2015;2(1):51-61.

98. Kubo JT, Henderson MT, Desai M, Wactawski-Wende J, Stefanick ML, Tang JY. Alcohol consumption and risk of melanoma 
and non-melanoma skin cancer in the Women's Health Initiative. Cancer Causes Control. 2014;25(1):1-10.

99. Siiskonen S, Han J, Li T, Cho E, Nijsten T, Qureshi A. Alcohol intake is associated with increased risk of squamous cell carcinoma of the skin: three US prospective cohort studies. Nutr Cancer. 2016;68(4):545-553.

100.Zhang Y, et al. Alcohol intake and early-onset basal cell carcinoma in a case-control study. Br J Dermatol. 2014;171(6):1451-1457.

101. Pirie K, et al. Heterogeneous relationships of squamous and basal cell carcinomas of the skin with smoking: the UK Million Women Study and meta-analysis of prospective studies. Br J Cancer. 2018;119(1):114-120.

102. Guo HR, Yu HS, Hu H, Monson RR. Arsenic in drinking water and skin cancers: cell-type specificity (Taiwan, ROC). Cancer Causes Control. 2001;12(10):909-916.

103. Naujokas MF, et al. The broad scope of health effects from chronic arsenic exposure: update on a worldwide public health problem. Environ Health Perspect. 2013;121(3):295-302.

104. Castrén K, Ranki A, Welsh JA, Vähäkangas KH. Infrequent p53 mutations in arsenic-related skin lesions. Oncol Res. 1998;10(9):475-482.

105. Hunt KM, Srivastava RK, Elmets CA, Athar M. The mechanistic basis of arsenicosis: pathogenesis of skin cancer. Cancer Lett. 2014;354(2):211-219.

106. Lee $\mathrm{CH}$, et al. Effects and interactions of low doses of arsenic and UVB on keratinocyte apoptosis. Chem Res Toxicol. 2004;17(9):1199-1205

107. Duffield-Lillico AJ, et al. Selenium supplementation and secondary prevention of nonmelanoma skin cancer in a randomized trial. J Natl Cancer Inst. 2003;95(19):1477-1481.

108. Gallagher RP, et al. Chemical exposures, medical history, and risk of squamous and basal cell carcinoma of the skin. Cancer Epidemiol Biomarkers Prev. 1996;5(6):419-424.

109. Wheeler BW, Allen J, Curnow A. Radon and skin cancer in southwest England: an ecologic study. Epidemiology. 2012;23(1):44-52.

110. Siddens LK, et al. Polycyclic aromatic hydrocarbons as skin carcinogens: comparison of benzo[a]pyrene, dibenzo[def,p]chrysene and three environmental mixtures in the FVB/N mouse. Toxicol Appl Pharmacol. 2012;264(3):377-386.

111. Chen HM, Lee YH, Wang YJ. ROS-triggered signaling pathways involved in the cytotoxicity and tumor promotion effects of pentachlorophenol and tetrachlorohydroquinone. Chem Res Toxicol. 2015;28(3):339-350.

112. Harwood CA, Leedham-Green M, Leigh IM, Proby CM. Low-dose retinoids in the prevention of cutaneous squamous cell carcinomas in organ transplant recipients: a 16-year retrospective study. Arch Dermatol. 2005;141(4):456-464.

113. Bavinck JN, et al. Prevention of skin cancer and reduction of keratotic skin lesions during acitretin therapy in renal transplant recipients: a double-blind, placebo-controlled study. J Clin Oncol. 1995;13(8):1933-1938.

114. Ulrich C, et al. Prevention of non-melanoma skin cancer in organ transplant patients by regular use of a sunscreen: a 24 months, prospective, case-control study. Br J Dermatol. 2009;161(Supp1_3):78-84.

115. Silverberg MJ, Leyden W, Warton EM, Quesenberry CP, Engels EA, Asgari MM. HIV infection status, immunodeficiency, and the incidence of non-melanoma skin cancer. J Natl Cancer Inst. 2013;105(5):350-360.

116. Zhao H, Shu G, Wang S. The risk of non-melanoma skin cancer in HIV-infected patients: new data and meta-analysis. Int $J$ STD AIDS. 2016;27(7):568-575.

117. Aasi S, et al. New onset of keratoacanthomas after vismodegib treatment for locally advanced basal cell carcinomas: a report of 2 cases. JAMA Dermatol. 2013;149(2):242-243.

118. Iarrobino A, Messina JL, Kudchadkar R, Sondak VK. Emergence of a squamous cell carcinoma phenotype following treatment of metastatic basal cell carcinoma with vismodegib. J Am Acad Dermatol. 2013;69(1):e33-e34

119. Orouji A, Goerdt S, Utikal J, Leverkus M. Multiple highly and moderately differentiated squamous cell carcinomas of the skin during vismodegib treatment of inoperable basal cell carcinoma. Br J Dermatol. 2014;171(2):431-433.

120. Zhu GA, Sundram U, Chang AL. Two different scenarios of squamous cell carcinoma within advanced Basal cell carcinomas: cases illustrating the importance of serial biopsy during vismodegib usage. JAMA Dermatol. 2014;150(9):970-973.

121. Mohan SV, Chang AL. Management of cutaneous and extracutaneous side effects of smoothened inhibitor therapy for advanced basal cell carcinoma. Clin Cancer Res. 2015;21(12):2677-2683.

122. Montaudié H, Chiaverini C, Sbidian E, Charlesworth A, Lacour JP. Inherited epidermolysis bullosa and squamous cell carcinoma: a systematic review of 117 cases. Orphanet J Rare Dis. 2016;11(1):117.

123. Lucky AW, Dagaonkar N, Lammers K, Husami A, Kissell D, Zhang K. A comprehensive next-generation sequencing assay for the diagnosis of epidermolysis bullosa. Pediatr Dermatol. 2018;35(2):188-197.

124. Sumpter R, Levine B. Emerging functions of the Fanconi anemia pathway at a glance. J Cell Sci. 2017;130(16):2657-2662.

125. Burger B, Itin PH. Epidermodysplasia verruciformis. Curr Probl Dermatol. 2014;45:123-131. 